\title{
Nonlinear Performance Characteristics of Flux-Switching PM Motors
}

\author{
E. Ilhan, M. F. J. Kremers, T. E. Motoasca, J. J. H. Paulides, and E. A. Lomonova \\ Department of Electrical Engineering, Electromechanics and Power Electronics (EPE) Group, Eindhoven University of Technology, \\ Den Dolech 2, 5612 AZ Eindhoven, The Netherlands \\ Correspondence should be addressed to E. Ilhan; e.ilhan@tue.nl
}

Received 31 August 2012; Accepted 25 October 2012

Academic Editor: Kyoung Kwan Ahn

Copyright (C) 2013 E. Ilhan et al. This is an open access article distributed under the Creative Commons Attribution License, which permits unrestricted use, distribution, and reproduction in any medium, provided the original work is properly cited.

\begin{abstract}
Nonlinear performance characteristics of 3-phase flux-switching permanent magnet motors (FSPM) are overviewed. These machines show advantages of a robust rotor structure and a high energy density. Research on the FSPM is predominated by topics such as modeling and machine comparison, with little emphasis given on its performance and limits. Performance characteristics include phase flux linkage, phase torque, and phase inductance. In the paper, this analysis is done by a crosscorrelation of rotor position and armature current. Due to the high amount of processed data, which cannot be handled analytically within an acceptable time period, a multistatic 2D finite element model (FEM) is used. For generalization, the most commonly discussed FSPM topology, 12/10 FSPM, is chosen. Limitations on the motor performance due to the saturation are discussed on each characteristic. Additionally, a focused overview is given on energy conversion loops and $d q$-axes identification for the FSPM.
\end{abstract}

\section{Introduction}

Nonlinear magnetic behaviour is a common phenomenon in electromechanical systems, that are pushing the boundaries. An example of such a system is flux-switching permanent magnet (FSPM) motor. This motor provides significant advantages such as a robust rotor structure, high speed capability, and high energy density. In the FSPM, the dominant nonlinear behaviour is a result of rotor position and armature current variations [1]. During these variations, both the field due to the PMs and armature current build up a parallel magnetic circuit, which boosts the magnetic field in the iron core.

Common practice shows that to account for the nonlinear magnetic behaviour, analytical models make use of external data obtained either by numerical models or by measurements [2]. Over the last decade, analytical nonlinear modeling of the FSPM has been under intensive research [3-7]. However, such models are very sensitive to the high amount of processed data and are not suitable for a performance analysis, where rotor position and armature current need to be varied. With the performance analysis, operational limits, flux weakening capabilities, and drive issues, depending on the inductance behaviour of the FSPM, can be determined.

In the limited amount of publications regarding the performance analysis of the FSPM, the general focus is set on the comparison with machines such as brushless $\mathrm{AC} / \mathrm{DC}$ and double salient machines $[8,9]$. In this paper, a detailed overview is given on the nonlinear performance characteristics of the FSPM. To generalize the findings, the most common topology of the FSPM is chosen, that is, the 3phase 12/10 with PM excitation, as shown in Figure $1[4,6,8]$. For the performance-characteristic-calculations, a 2D finite element model (FEM) of the FSPM is created using Flux software. In the parametrization process, a direct link to the MATLAB environment is made, where the armature current $i$ and rotor position $\theta_{m}$ are varied for a cross-correlated analysis. For the armature current, a constant current is varied from $[0: 100] \mathrm{A}-\mathrm{rms}$ with $\Delta i=5 \mathrm{~A}$-rms intervals, whereas the rotor position is varied for one electrical cycle $\theta_{m}=[0: 36]^{\circ}$. The upper limit of current is set to ten times the rated current $I_{n}=10 \mathrm{~A}$ to evaluate the performance characteristics of the machine. In the paper, each section introduces a different performance characteristic explaining 


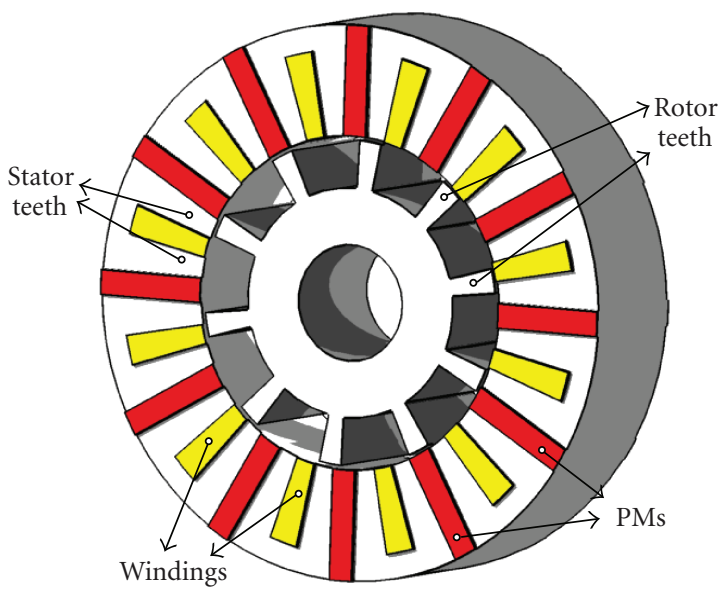

FIGURE 1: A 3D illustration of the FSPM with 12 stator poles and 10 rotor teeth.

under which conditions the calculations are performed, followed by discussions about the results. The calculated characteristics include phase flux linkage, torque components and commutation, and machine inductance.

\section{FEM Model}

The finite element model (FEM) of the 12/10 FSPM is created by the Flux software. The geometrical model with the mesh elements are given in Figure 2. The 2D FEM model is a magnetostatic model, which is solved using magnetic vector potential. In order to investigate the local and global nonlinear magnetic behaviour, cobalt-iron is used as the soft magnetic material with the properties explained in Section 4.1.For this study, a fine mesh is created with an overall number of 19658 mesh nodes, 3029 lines, and 9306 triangular mesh elements. Alternating permanent magnets (PMs) are circumferentially magnetized. The $12 \mathrm{PMs}$ located in the stator are linearly described with a remanent flux density of $B_{r}=1.2 \mathrm{~T}$ and a relative permeability of $\mu_{r}=1.05$. For the nonlinear calculations, Newton-Raphson algorithm is used with a relaxation factor, which is calculated by the Fujiwara method.

\section{Phase Flux Linkage}

2D FEM calculations of the FSPM are based on the vector magnetic potential, $\vec{A}$, whereas $3 \mathrm{D}$ models are solved generally with the scalar magnetic potential. The $\vec{A}_{z}$ vector component is calculated in the nodes of the triangular mesh elements for each coil region of phase-A in Figure 3. The derived phase flux linkage, $\lambda$, depends on both armature current and rotor position. Each graph in Figure 4 represents the phase flux linkage for a given current value. At $\theta_{m}=0^{\circ}$, the rotor tooth and PM are aligned ( $q$-axis) as illustrated in Figure 3.

Up to four times the rated value $I_{n}=10 \mathrm{~A}$, the increase in phase flux linkage amplitude in Figure 4(a) is constant. Once saturation becomes dominant, around $40 \mathrm{~A}$, the increase becomes nonlinear gradually with increasing current. It limits the torque capability of the FSPM due to the energy conversion in the motor. This conversion can be visualized by energy conversion loops, which are created by transient-flux linkage current $(\lambda(t)-i(t))$ [10]. Looking at the nonlinear energy conversion loops in Figure 4(b), the $40 \mathrm{~A}$-limit corresponds to the point where the loop begins to change from a perfect ellipse to a flat ellipse. The area of each energy conversion loop in Figure 4(b) corresponds to the average torque output at that current.

\section{Electromagnetic Torque}

By applying the Maxwell Stress Tensor (MST) in the middle of the airgap, the maximum torque capability of the machine is calculated as a function of the phase current. In Figure 5(a), static torque characteristics depending on the rotor position are shown. The rated torque values in Figure 5(b) illustrate the torque capability of the FSPM. The maximum torque of each graph in Figure 5(a) is the maximum average electromagnetic torque which can be achieved at the given current level. Similar to the flux linkage characteristics, the nonlinear relationship between the armature current and the rated torque begins at four times the rated current, hence around $40 \mathrm{~A}$.

4.1. Cogging Torque. As the armature current increases, torque versus position in Figure 5(a) becomes more sinusoidal. If cogging torque is assumed to be independent of saturation, one possible explanation is that the cogging torque could be less apparent in the torque ripple. To verify this statement, an additional study is done.

The stator back iron is decomposed into 12 smaller elements as in Figure 3, where each element is assumed to have a different magnetic operating point on the soft magnetic material. The effective relative permeability $\mu_{r}$ of each element is written as a function of the rotor position $\theta_{m}$ and current $i$. Next, these $\mu_{r}$ values are implemented in the grid elements of the zero current FEM model. This way, FSPM at zero current is brought "artificially" to the magnetic working point, which would be actually achieved at corresponding current levels. For this analysis, three significant current levels are chosen as $0 \mathrm{~A}, 10 \mathrm{~A}$ (rated current), and $100 \mathrm{~A}$. In Table 1, effective $\mu_{r}$ and $|B|$ values are given for the three current levels. This table indicates which part of the stator back is more sensitive to the changes in the magnetic field.

Considering the simulation time, cogging torque $T_{c}$ in Figure $6(\mathrm{a})$ is calculated over one stator period by using the MST method. For the remaining 11 stator periods, $T_{c}$ is shifted by $\Delta \theta_{m}=6^{\circ}$ for each period and superimposed using:

$$
T_{\operatorname{cog}}=\sum_{k=0}^{11} T_{c}\left(\theta_{m}-k \Delta \theta_{m}\right)
$$

where $T_{\operatorname{cog}}$ is the total cogging torque of the FSPM, as shown in Figure 6(b). These results verify the original statement that the cogging torque is independent of the machine saturation, that is, it is not affected by increasing current. This result 


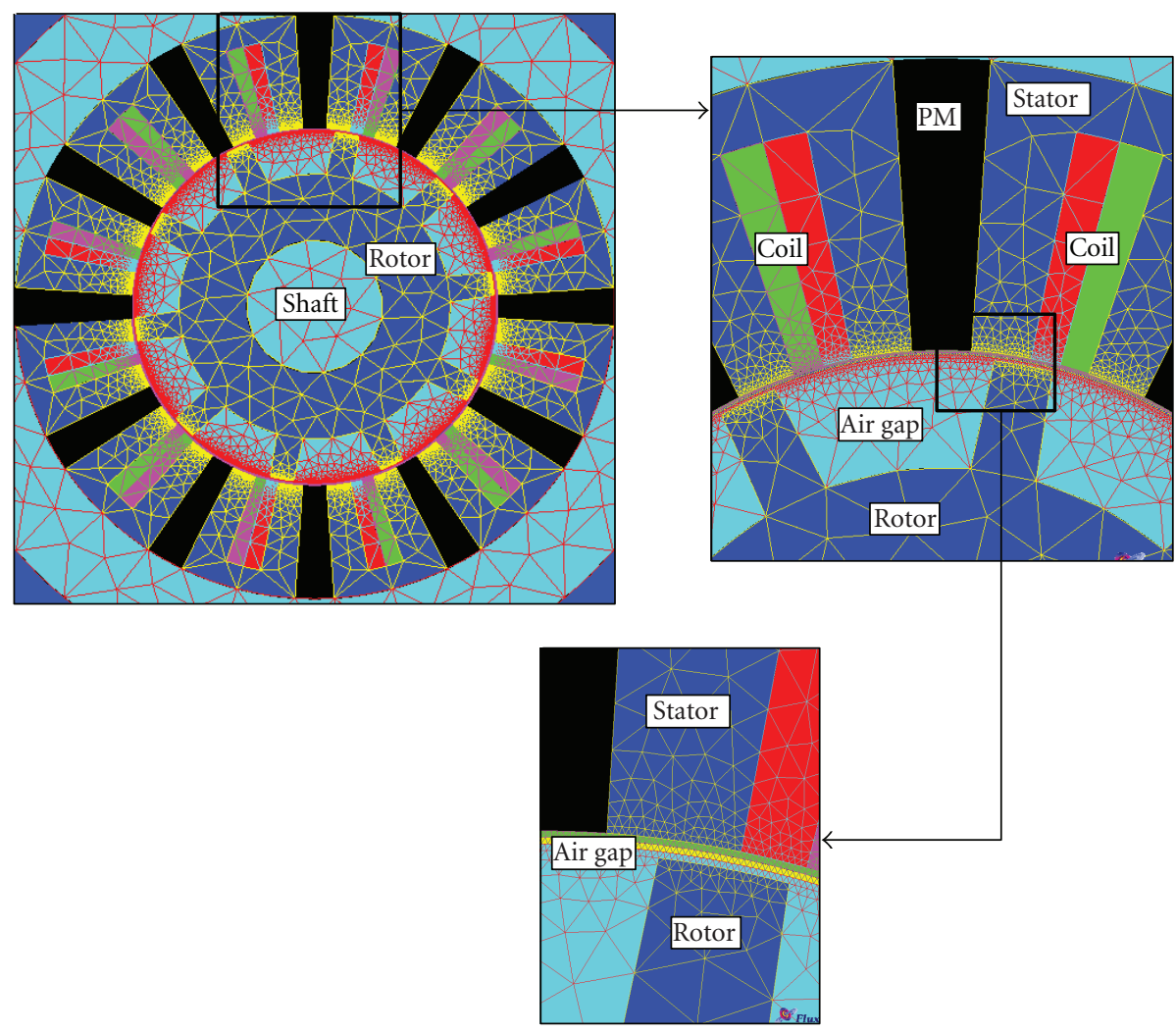

FIGURE 2: FEM model of the 12/10 FSPM used in the calculations.

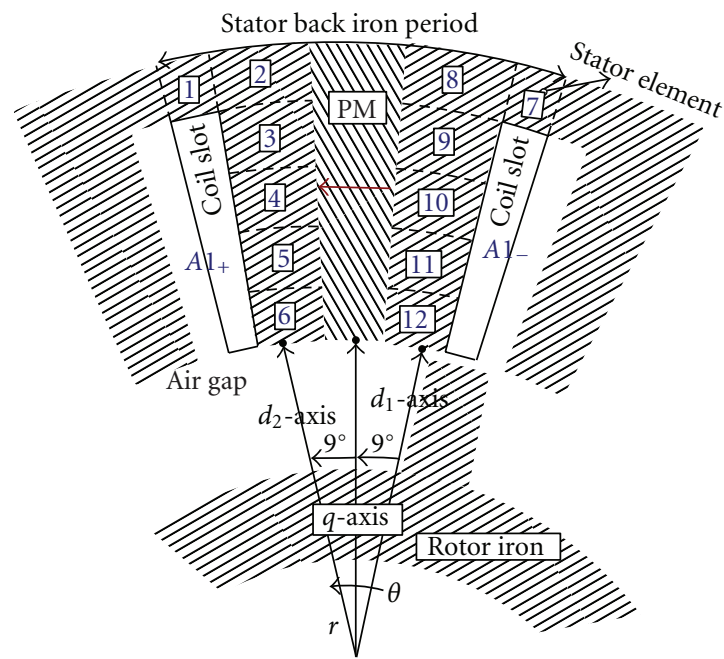

FIGURE 3: Definitions of the $d q$-axes of the $12 / 10$ FSPM on one stator period along with the grid elements used in the cogging torque analysis.

indicates that airgap permeance is still dominant in the magnetic circuit responsible for the cogging.

For the study of cogging torque investigation, two different soft magnetic materials are used with the magnetic characteristics given in Figures 7(a)-7(b). The first material considered is cobalt-iron, which is commonly chosen for applications with high saturation requirement, such as in FSPM motors. The saturation level of this material is around 2.3 T. Due to its high cost and the difficulties with machining and grinding of this material, it is not commonly used in electrical machines. Cobalt-iron is considered in this study only due to its higher remanence value.

The second material M400-50 A in Figures 7(a)-7(b) is a commonly used electric steel (transil). M400-50 A is chosen to test how material choice affects this study. In practice, it is a commonly used material for electrical machines.

In a saturated grid element (ele. 1) and a nonsaturated one (ele. 6), both materials are used to calculate the effective flux 


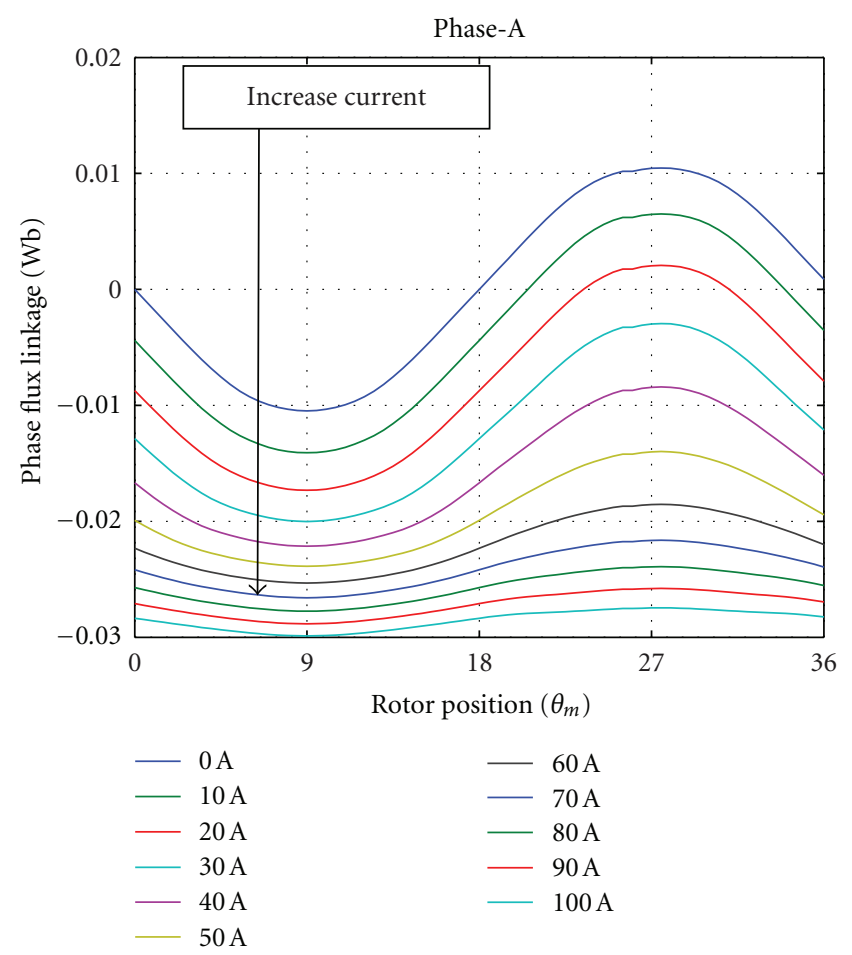

(a)

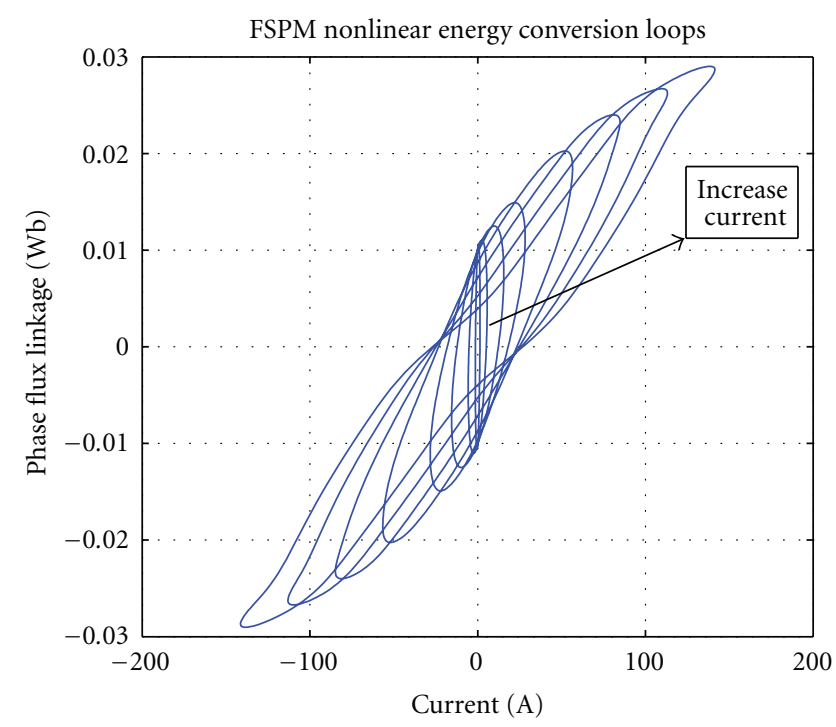

FIGURE 4: (a) Phase flux linkage with increasing current, (b) nonlinear energy conversion loops of the FSPM.

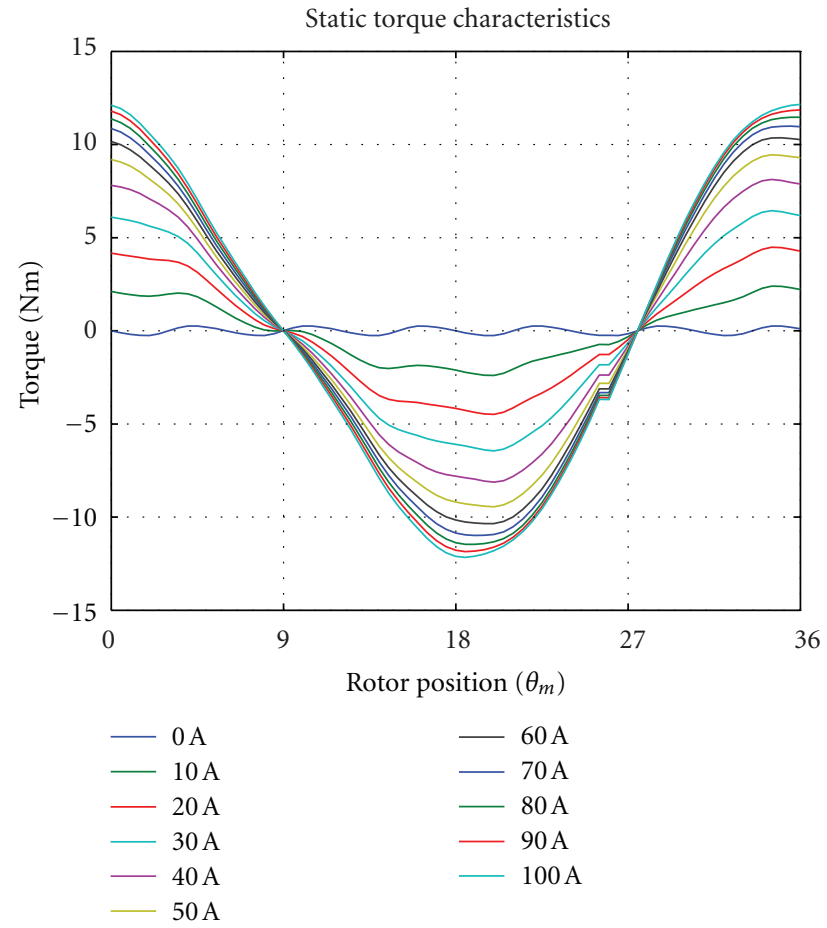

(a)

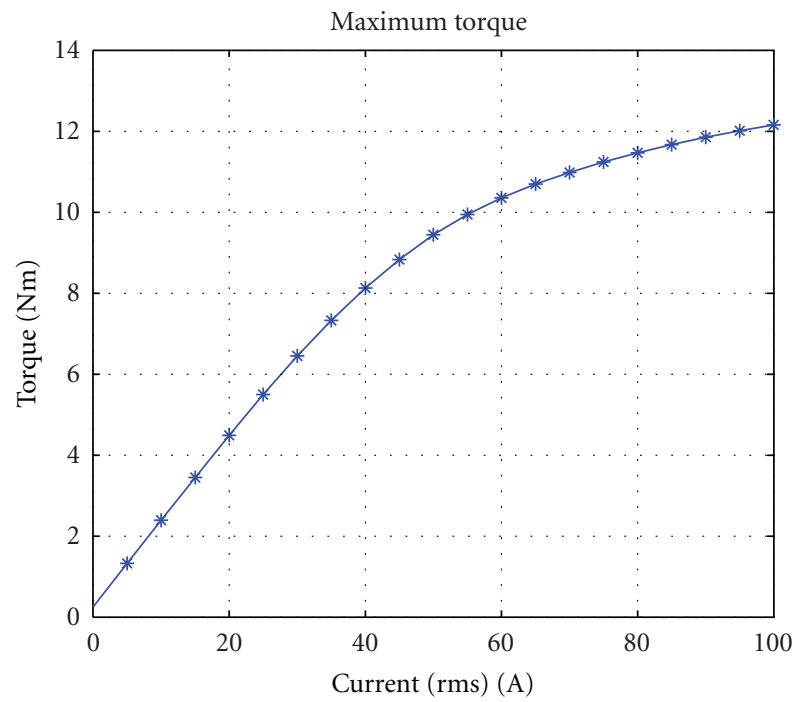

FIGURE 5: (a) Static torque calculations with increasing current, (b) nominal output torque varying with armature current. 


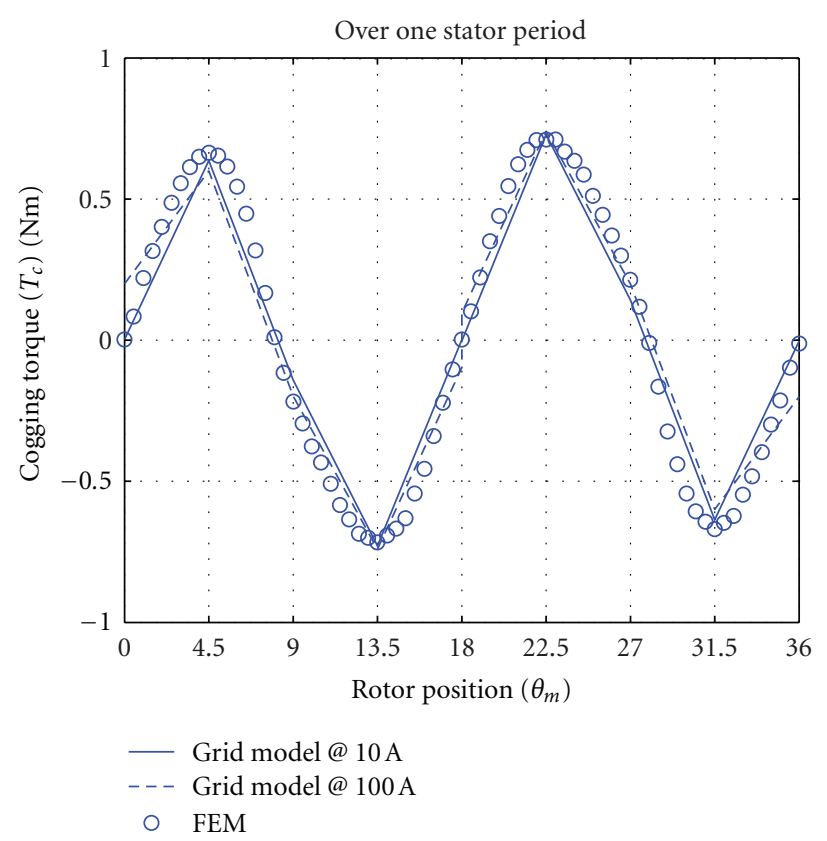

(a)

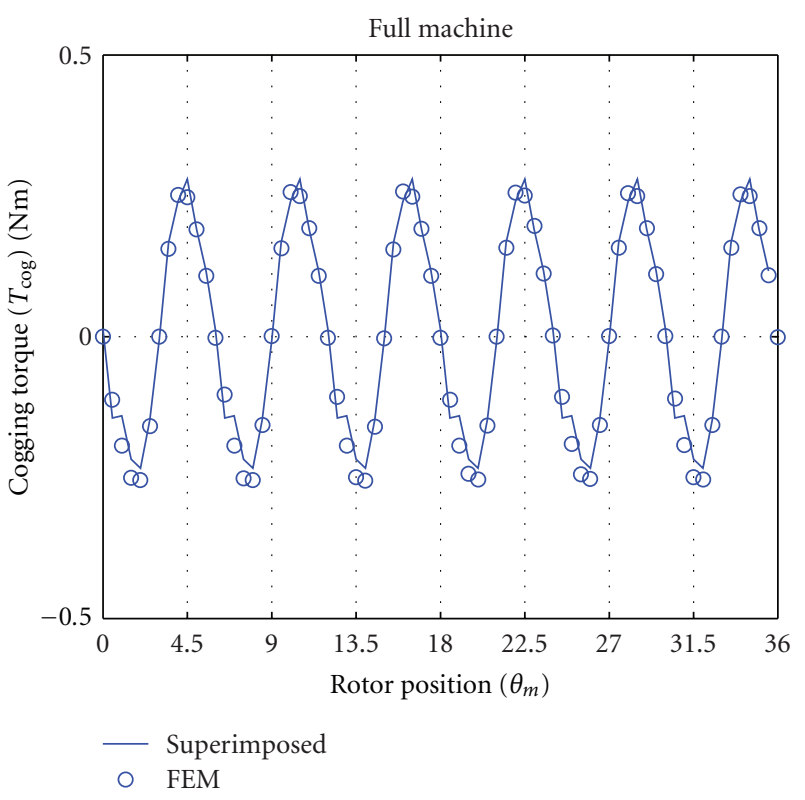

(b)

FIGURE 6: (a) Cogging torque calculations on one stator period and (b) on the full machine.

TABLE 1: Effective $\mu_{r}$ and $|B|$ values at different current levels.

\begin{tabular}{lcccccc}
\hline \multirow{2}{*}{ Element no. } & \multicolumn{3}{c}{ Relative permeability $\mu_{r}$} & \multicolumn{3}{c}{ Flux density $|B|[T]$} \\
& $0 \mathrm{~A}$ & $10 \mathrm{~A}$ & $100 \mathrm{~A}$ & $0 \mathrm{~A}$ & $10 \mathrm{~A}$ & $100 \mathrm{~A}$ \\
\hline 1 & 5016 & 4392 & 14 & 0.53 & 0.4 & 2.25 \\
2 & 4388 & 4536 & 553 & 0.2 & 0.32 & 1.66 \\
3 & 5093 & 4610 & 213 & 0.5 & 0.37 & 1.8 \\
4 & 4937 & 4945 & 415 & 0.78 & 0.53 & 1.7 \\
5 & 3537 & 4564 & 2156 & 1.16 & 0.88 & 1.42 \\
6 & 2128 & 2966 & 4804 & 1.5 & 1.27 & 0.88 \\
7 & 5256 & 4379 & 24 & 0.64 & 0.45 & 2.18 \\
8 & 5143 & 4738 & 2329 & 0.51 & 0.36 & 1.1 \\
9 & 4987 & 4636 & 529 & 0.43 & 0.39 & 1.67 \\
10 & 4344 & 4879 & 73 & 0.34 & 0.53 & 2 \\
11 & 4909 & 5121 & 27 & 0.53 & 0.8 & 2.1 \\
12 & 5016 & 4561 & 81 & 0.79 & 1 & 2 \\
\hline
\end{tabular}

density levels in the stator back iron. Results in Figure 7 (c) show a difference of $0.05 \mathrm{~T}$ for the nonsaturated and $0.1 \mathrm{~T}$ for the saturated grid element. The kind of soft magnetic material does not affect the FSPM profiles but only puts a DC-shift in the calculations.

4.2. Torque Commutation Angle. For field weakening, it is important to know the torque-commutation angle characteristic. To get this characteristic, the rotor is fixed at the $q$-axis during the simulations. For this simulation, current depends only on commutation angle $\phi$ in the form $I(\phi)=$ $I_{\max } \sin (\phi)$. The commutation angle $\phi$ is varied $[0: 180]^{\circ}$ for half an electrical cycle. In Figure 8, there is a slight electrical shift, $7.5^{\circ}$, of the maxima. Due to slotting, torque does not reach its maximum value at $90^{\circ}$. For the control of the FSPM, this shift is almost negligible in mechanical degrees, which also indicates a negligible reluctance torque.

\section{Inductance Calculations}

In literature, there are several mathematical definitions for inductances [11]. They can be described as apparent (static, absolute, normal) or incremental (differential) inductances. Although the number of turns are included in the inductance calculations, end turn inductances are neglected in $2 \mathrm{D}$ models.

Static inductance of a phase coil gives the linear relationship between the total flux $\lambda$ linked by the coil and its current $i$ as

$$
L=\frac{\lambda}{i}
$$

To obtain the incremental inductance $\Delta L\left(\theta_{m}\right)$, the difference of the phase flux linkage $\Delta \lambda$ is divided by the difference of the corresponding current $\Delta i$ :

$$
\Delta L\left(\theta_{m}\right)=\frac{\Delta \lambda\left(\theta_{m}\right)}{\Delta i}=\frac{\left.\lambda\left(\theta_{m}\right)\right|_{i_{2}}-\left.\lambda\left(\theta_{m}\right)\right|_{i_{1}}}{\left.i_{2}\right|_{\text {cons. }}-\left.i_{1}\right|_{\text {cons. }}} .
$$

For linear magnetic materials, both methods yield identical results. However in the nonlinear region, the crosscoupling (cross-saturation) greatly affects $d q$-inductance calculations and only the incremental inductance can account for this effect. The results are presented in Figure 9. At rotor 


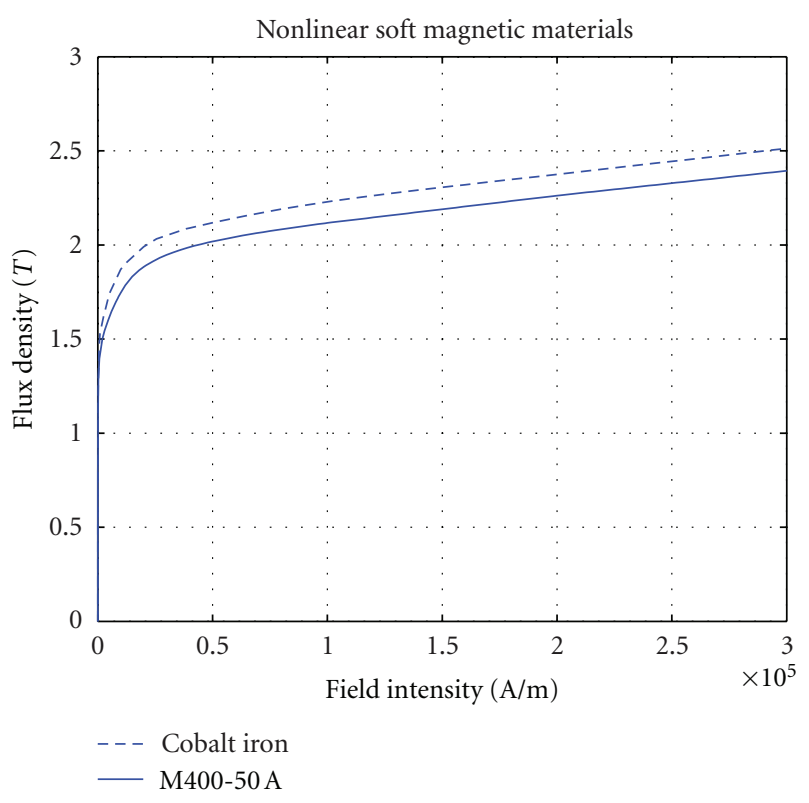

(a)

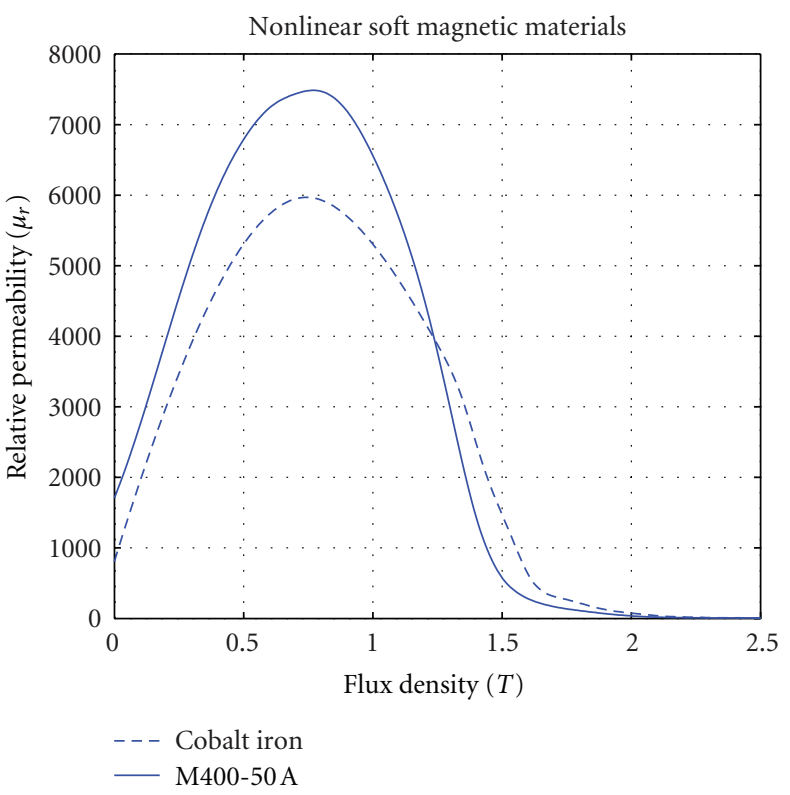

(b)
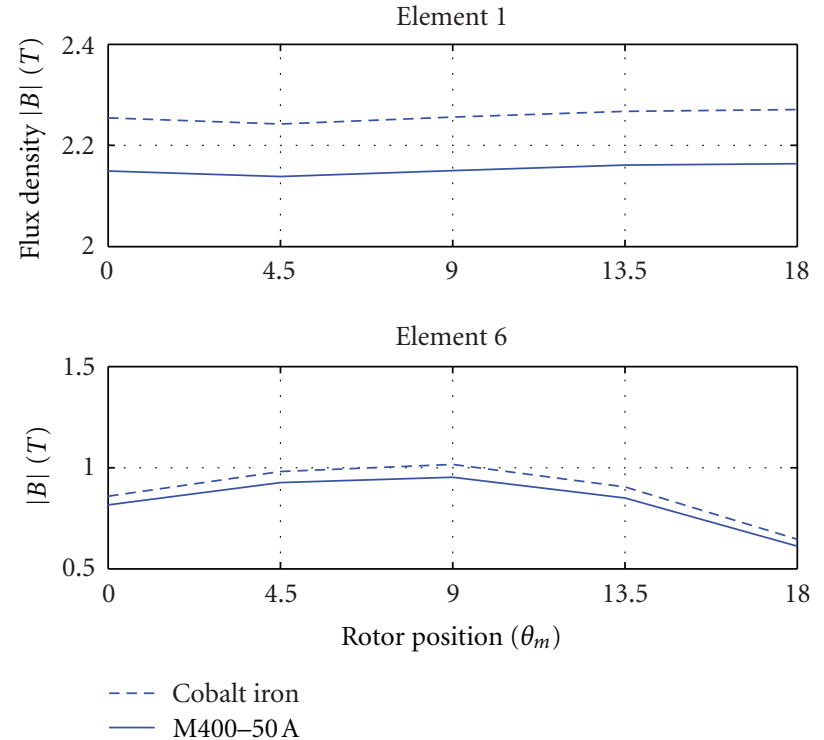

(c)

Figure 7: (a) $B(H)$ curves different soft magnetic materials, (b) $\mu_{r}(B)$ curves different soft magnetic materials, (c) Flux density profiles with different materials.

positions $\theta_{m}=[0: 10.5]^{\circ}$ and $\theta_{m}=[28.5: 36]^{\circ}$ up to four times the rated current (limit for machine saturation), the phase inductance tends to increase. Since $\Delta i$ is constant, the increase of inductance values is due to the increase of $\Delta \lambda\left(\theta_{m}\right)$.

\section{6. $d q$-Axes Identification}

Flux switching machines have similar phase flux linkage as the switched reluctance machines (SRM), however with the advantage of being bipolar. The incremental inductance at 0 A in Figure 9(a) resembles a typical SRM inductance profile with double frequency. The $d$-axis alignment occurs at the sides of each magnet. These two $d$-axes are $180^{\circ}$ electrical apart from each other, which correspond mechanically to $18^{\circ}$ for $12 / 10$ FSPM. A similar definition can also be made for the $q$-axis. The $q$-axis alignment occurs at magnet-rotor tooth alignment and magnet-rotor slot alignment. These inductance definitions are illustrated in Figure 10.

Based on the $d q$-axes definitions in Figure 10, the $d q$ inductances $\left(L_{d 1, d 2}\right.$ and $\left.L_{q 1, q 2}\right)$ are given in Figure $9(\mathrm{~b})$ as functions of $d q$-currents $\left(I_{d, q}\right)$, respectively. If $d_{2}$ is chosen as the $d$-axis of the FSPM, $L_{d 2}$ corresponds to the minimum inductance and $L_{q}$ corresponds to the maximum inductance. However, if $d_{1}$ is chosen as the $d$-axis, the inductance $L_{d 1}$ 


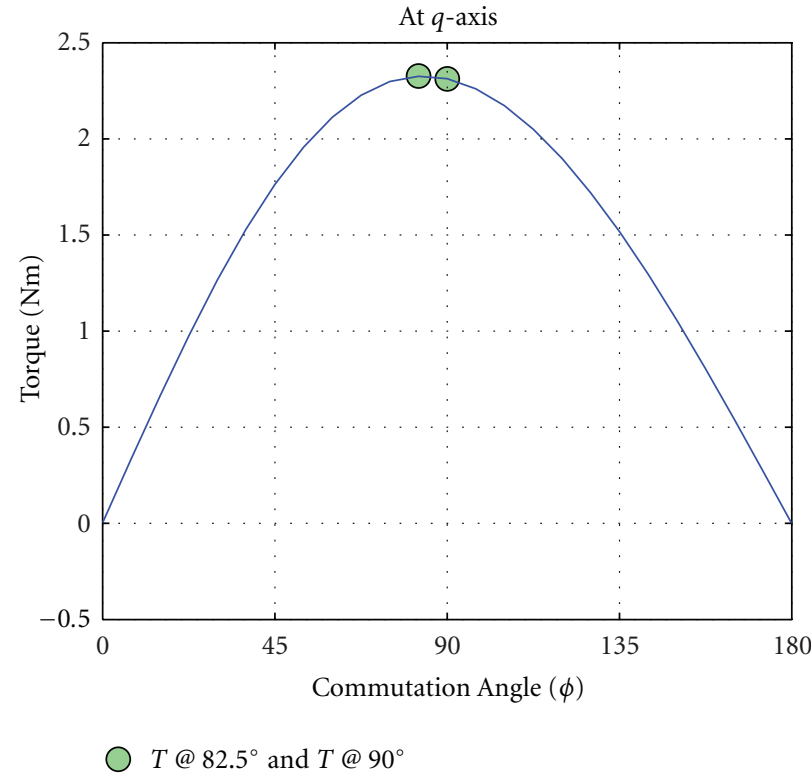

FIgURE 8: Torque versus commutation angle with rotor fixed at $q$-axis.

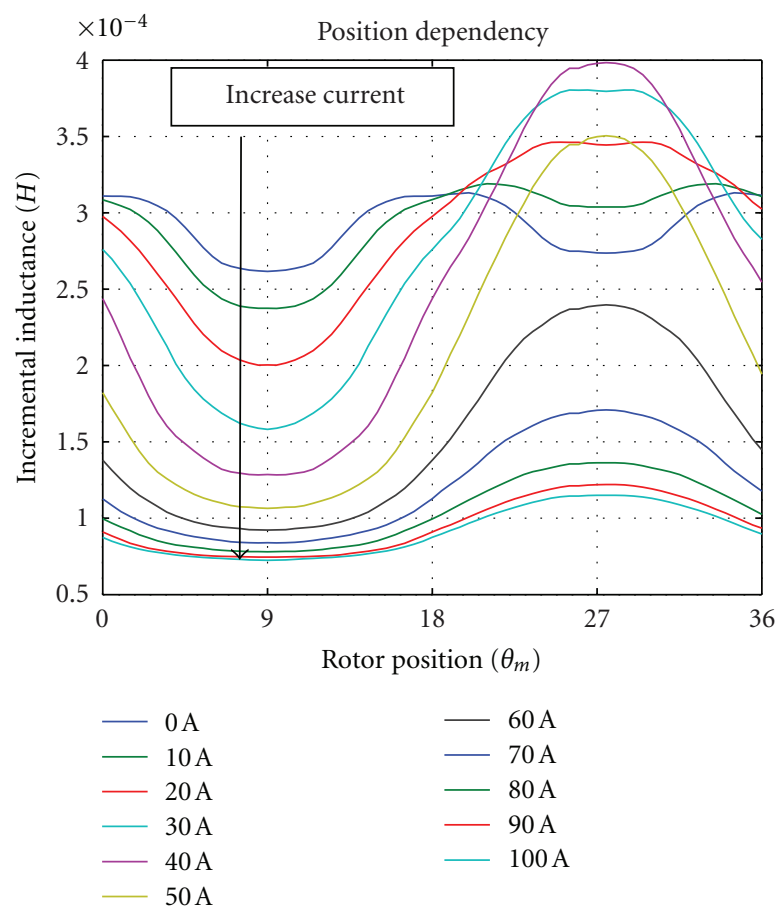

(a)

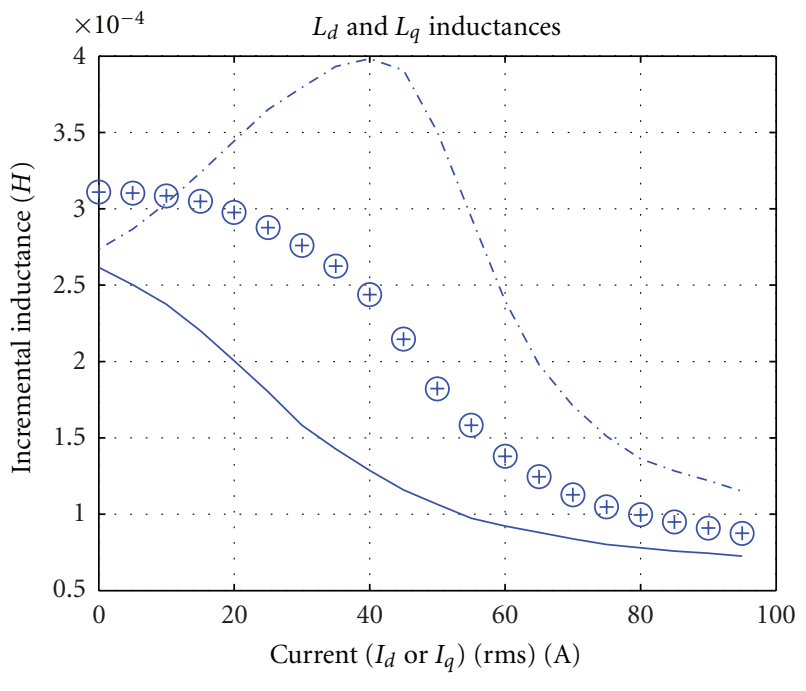

$\cdot-\cdot-L_{d 1}$

$\bigcirc \quad L_{q 1}$

$L_{d 2}$

(b)

FIGURE 9: (a) Incremental inductance, (b) $d q$ inductances $\left(L_{d 1, d 2}\right.$ and $\left.L_{q 1, q 2}\right)$ of the 12/10 FSPM including cross-coupling.

increases until $i=40 \mathrm{~A}$. Once the saturation starts, $L_{d 1}$ also decreases like $L_{d 2}$ and $L_{q}$. Up to $40 \mathrm{~A}$, the second derivative of the phase flux linkage $\left(d^{2} \lambda / d \theta_{m}^{2}\right)$ at $d_{1}$ and $d_{2}$ has different signs. Therefore, in this interval, $L_{d 1}$ and $L_{d 2}$ have different slopes. It is also the reason for the inductance increase in Figure 9(a). It should be noted that these are static calculations, whereas in the transient analysis, the phase flux linkage at $d_{1}$ and $d_{2}$ positions has identical values with opposite signs.

\section{Conclusions}

With their high torque density and robust and simple rotor structures, FSPMs have a significant application potential 


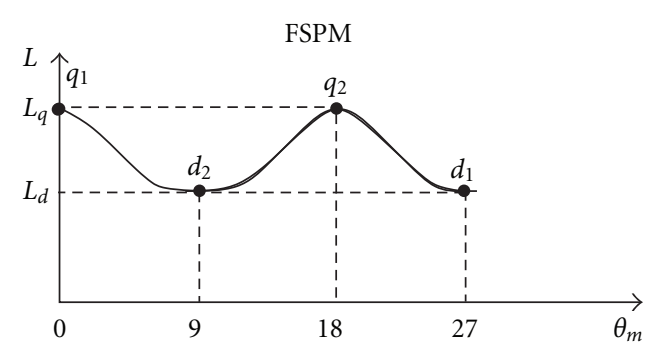

FIGURE 10: $d q$-axes identification for the 12/10 FSPM.

TABLE 2: FSPM size and parameters.

\begin{tabular}{lc}
\hline Number of phases & 3 \\
Rotor pole number & 10 \\
Stator pole number & 12 \\
Frame size & $90 \mathrm{~mm}$ \\
Stator inner diameter & $55 \mathrm{~mm}$ \\
Shaft diameter & $20 \mathrm{~mm}$ \\
Active stack length & $25 \mathrm{~mm}$ \\
Airgap & $0.5 \mathrm{~mm}$ \\
Number of turns per phase & 72 \\
Remanent flux density of permanent magnet & $1.2 \mathrm{~T}$ \\
Relative permeability of permanent magnet & 1.05 \\
Phase current (rms) & $10 \mathrm{~A}$ \\
Rated torque & $2.2 \mathrm{Nm}$ \\
Rated speed & $4400 \mathrm{rpm}$ \\
Power & $\sim 1 \mathrm{~kW}$ \\
\hline
\end{tabular}

among PM machines. This paper investigated FSPM's nonlinear magnetic behaviour in a general overview of the performance characteristics. Cross-correlating the armature current and rotor position gave information on the capabilities of the FSPM, with special emphasis on energy conversion loops, cogging torque, and $d q$-axes identification.

Findings showed a linear overloading capability of four times the rated current, however with specific impact on phase inductances. New $d q$-axes identification has been presented for the FSPM, to show the cross-coupling effect. Further on, it has been shown that cogging does not depend on the elevated current levels due to the dominating airgap permeance. Additionally, a negligible reluctance torque is found. Using energy conversion loops, the overloading capability is visualized, which indeed depends on additional elements such as thermal and mechanical aspects.

\section{Appendix}

See Table 2 .

\section{Nomenclature}

$I_{n}:$ Rated phase current

$\lambda$ : $\quad$ Phase flux linkage

$\Delta L$ : Incremental phase inductance

$\theta_{m}:$ Mechanical rotor position $i$ : Armature current

$\phi$ : Commutation angle

$T: \quad$ Torque

$T_{\text {cog: }}$ : Cogging torque

$\mu_{r}: \quad$ Relative permeability;

$d, q$ : Subscripts for direct-quadrature-axes quantities;

$k$ : $\quad$ Subscript for stator back-iron period.

\section{References}

[1] B. L. J. Gysen, E. Ilhan, K. J. Meessen, J. J. H. Paulides, and E. A. Lomonova, "Modeling of flux switching permanent magnet machines with fourier analysis," IEEE Transactions on Magnetics, vol. 46, no. 6, pp. 1499-1502, 2010.

[2] G. Štumberger, T. Marčič, B. Štumberger, and D. Dolinar, "Experimental method for determining magnetically nonlinear characteristics of electric machines with magnetically nonlinear and anisotropic iron core, damping windings, and permanent magnets," IEEE Transactions on Magnetics, vol. 44, no. 11, pp. 4341-4344, 2008.

[3] Y. Tang, T. E. Motoasca, J. J. H. Paulides, and E. A. Lomonova, "Investigation of winding topologies for flux switching machines," in Proceedings of the 15th International Symposium on Electromagnetic Fields in Mechatronics, Electrical and Electronic Engineering (ISEF '11), September 2011.

[4] E. Ilhan, B. L. J. Gysen, J. J. H. Paulides, and E. A. Lomonova, "Analytical hybrid model for flux switching permanent magnet machines," IEEE Transactions on Magnetics, vol. 46, no. 6, pp. 1762-1765, 2010.

[5] S. Zhou, H. Yu, M. Hu, C. Jiang, and L. Huang, "Nonlinear equivalent magnetic circuit analysis for linear flux-switching permanent magnet machines," IEEE Transactions on Magnetics, vol. 48, no. 2, Article ID Article number6136503, pp. 883-886, 2012.

[6] E. Ilhan, J. Paulides, and E. Lomonova, "Fast torque estimation of in-wheel parallel flux switching machines for hybrid trucks," COMPEL, vol. 31, no. 1, pp. 40-53, 2012.

[7] W. Hua, G. Zhang, M. Cheng, and J. Dong, "Electromagnetic performance analysis of hybrid-excited flux-switching machines by a nonlinear magnetic network model," IEEE Transactions on Magnetics, vol. 47, no. 10, pp. 3216-3219, 2011.

[8] B. Štumberger, G. Štumberger, M. Hadžiselimović et al., "Performance comparison of three-phase flux reversal permanent magnet motors in BLDC and BLAC operation mode," Journal of Magnetism and Magnetic Materials, vol. 320, no. 20, pp. e896-e900, 2008.

[9] W. Hua, M. Cheng, H. Jia, and X. Fu, "Comparative study of flux-switching and doubly-salient PM machines particularly on torque capability," in Proceedings of the IEEE Industry Applications Society Annual Meeting (IAS '08), pp. 1-8, October 2008.

[10] E. Ilhan, T. E. Motoasca, J. J. H. Paulides, and E. A. Lomonova, "Energy conversion loops for flux-switching pm machine analysis," in Proceedings of the 15th International Symposium on Electromagnetic Fields in Mechatronics, Electrical and Electronic Engineering (ISEF '11), September 2011.

[11] H. Jia, M. Cheng, W. Hua, W. Lu, and X. Fu, "Investigation and implementation of control strategies for flux-switching permanent magnet motor drives," in Proceedings of the IEEE Industry Applications Society Annual Meeting (IAS '08), pp. 1-6, October 2008. 

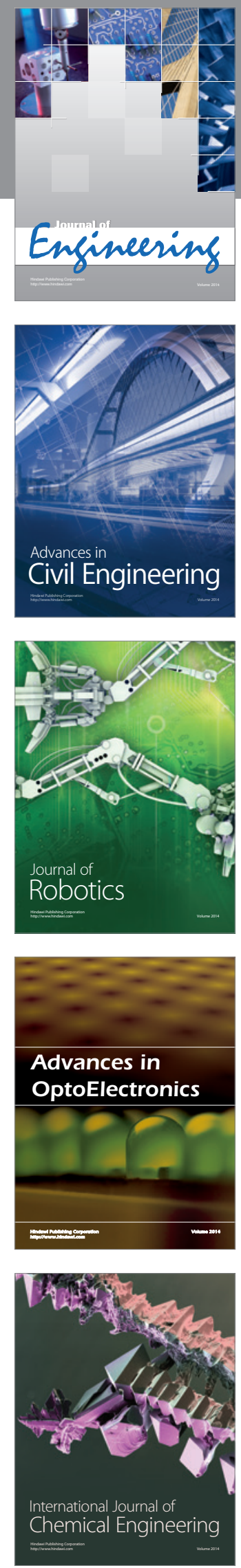

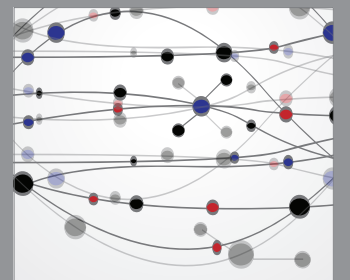

The Scientific World Journal
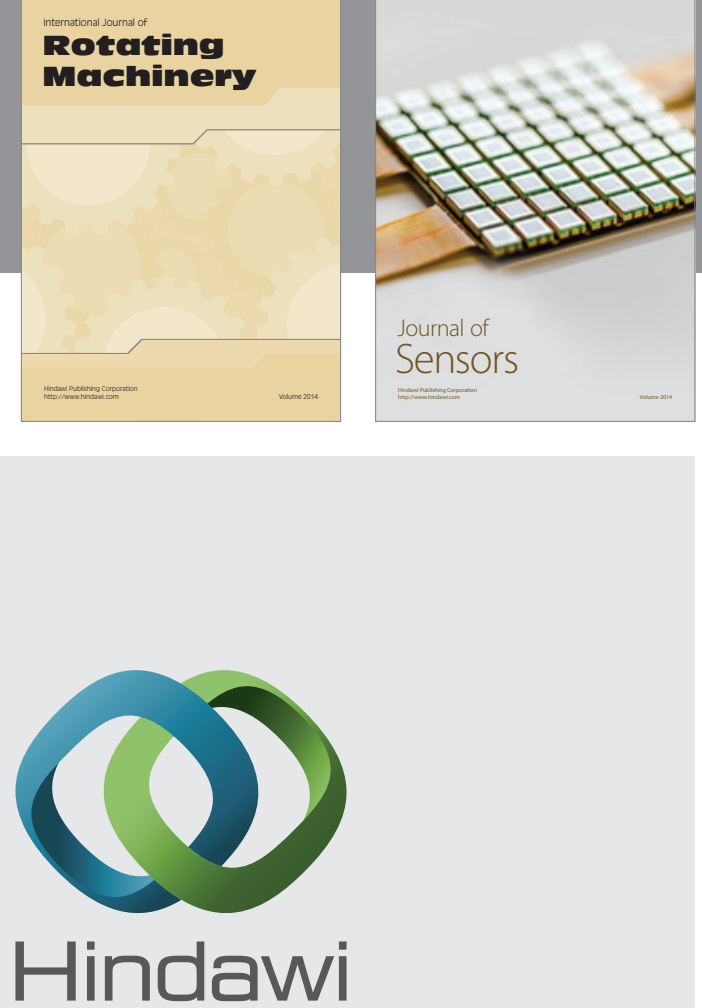

Submit your manuscripts at http://www.hindawi.com
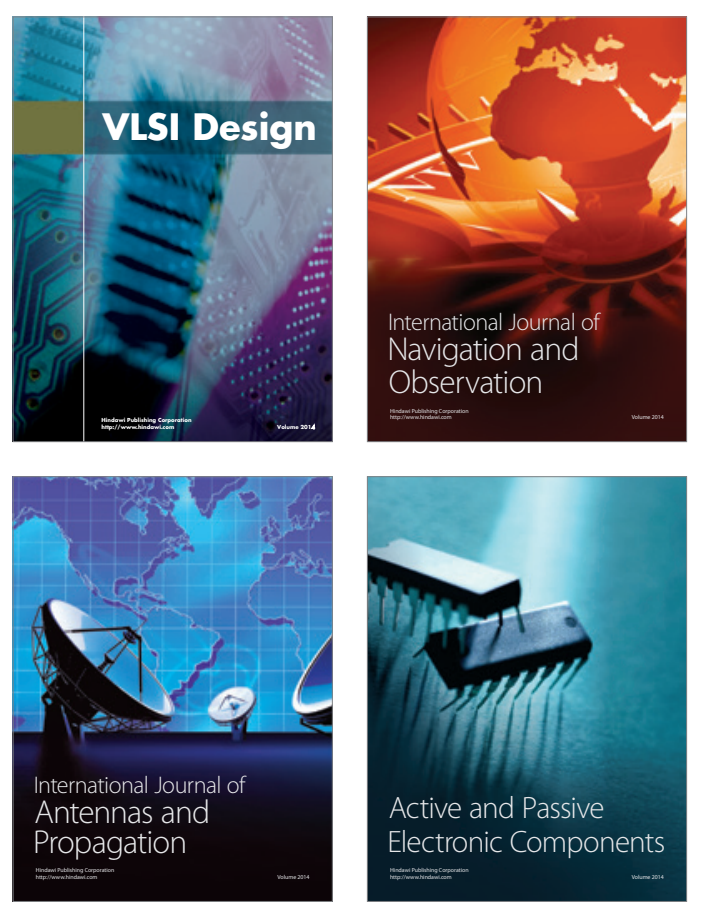
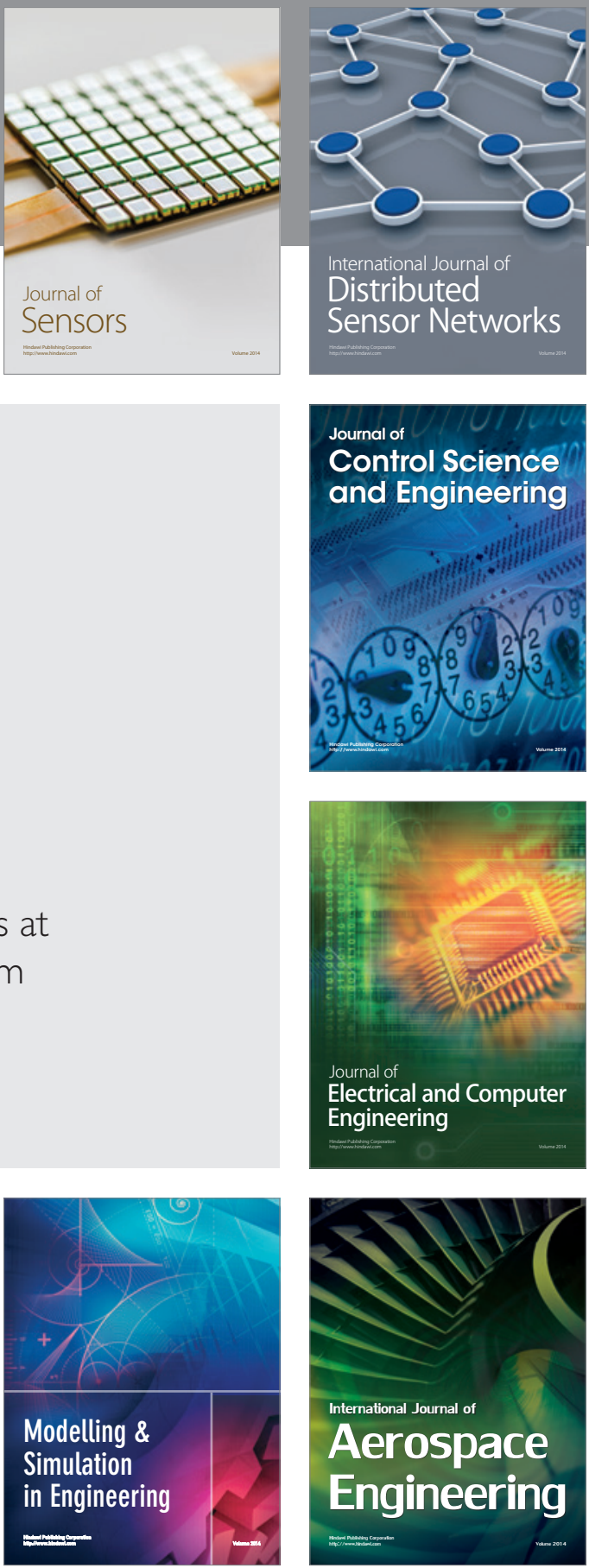

Journal of

Control Science

and Engineering
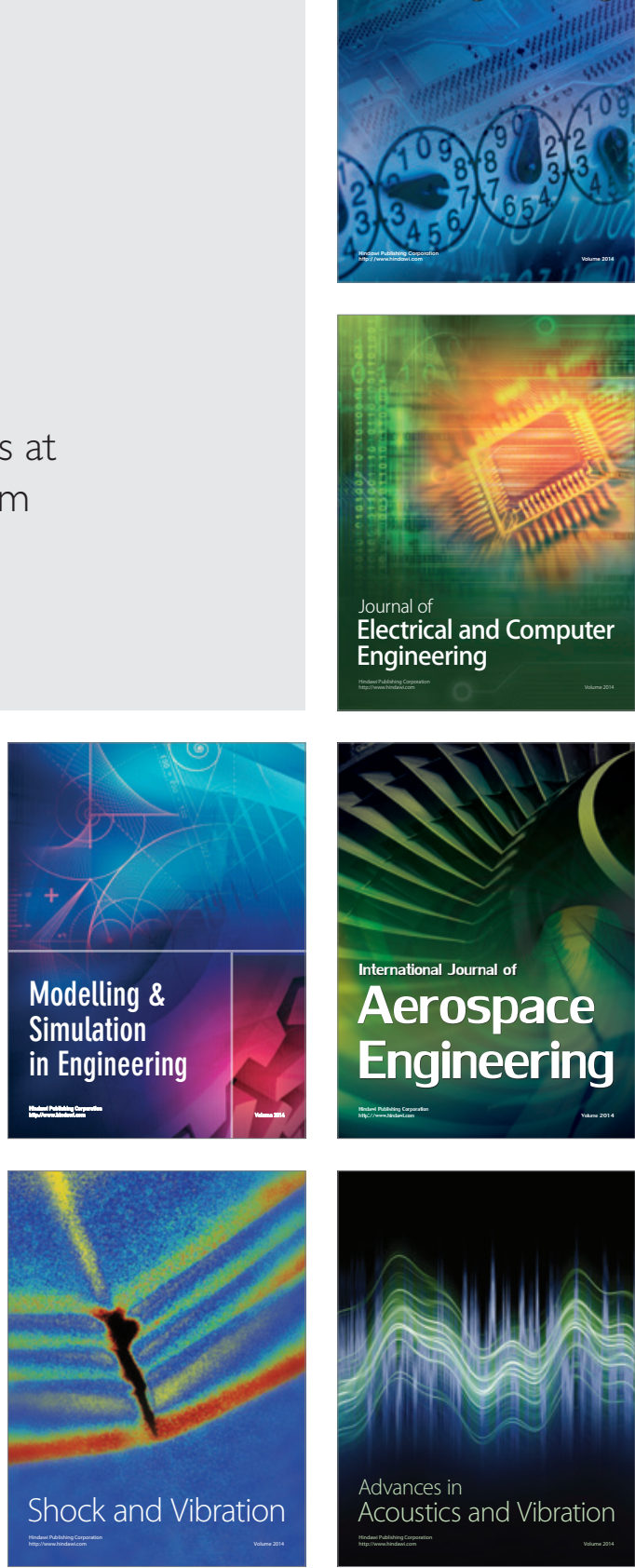